\title{
Ascensão social e mobilidade espacial de sírios e libaneses em Porto Alegre (1890-1949)
}

Social ascent and spacial mobility of syrian and lebanese in Porto Alegre (1890-1949)

\author{
Júlio C. Bittencourt Francisco ${ }^{*}$
}

\author{
Palavras-chave: \\ Imigração \\ Sírios e libaneses \\ Porto Alegre
}

Keywords:

Immigration

Syrian and Lebanese

Porto Alegre

\begin{abstract}
Resumo: $\mathrm{O}$ texto descreve as condições econômicas e sociais nas quais os imigrantes sírios e libaneses se integraram à vida cotidiana de Porto Alegre, desde o fim da última década do século XIX, até meados do século XX. A pesquisa descreve o início da saga desses imigrantes, cuja maioria era formada por mascates e pequenos comerciantes, quando ocuparam um pequeno trecho de rua no centro da capital até o seu deslocamento para diversos bairros da cidade. Esta trajetória é marcada, no início, por condições precárias de moradia, disputas dentro do grupo e violência, para um padrão de vida pontuada pela ascensão social e mobilidade espacial que também se reflete na matricula dos seus filhos em duas das melhores instituições de ensino da capital.
\end{abstract}

\begin{abstract}
The text describes the economic and social conditions in which the Syrian and Lebanese immigrants integrated into the daily life of Porto Alegre, from the end of the last decade of the 19th century until the middle of the 20th century. The survey describes the beginning of the saga of these immigrants, most of whom were paddlers and small merchants, when they occupied a small stretch of street in the center of the capital until their displacement to various districts of the city. This trajectory is marked, at the beginning, by precarious conditions of housing, disputes within the group and violence, to a standard of living punctuated by spatial mobility and social ascent that is reflected in the enrollment of their children in two of the best educational institutions of the capital.
\end{abstract}

Recebido em 09 de maio de 2018. Aprovado em 02 de agosto de 2018.

\section{Introdução}

Embora a maioria dos imigrantes sírios e libaneses que chegaram ao Rio Grande do Sul fosse formada por pequenos agricultores, a estrutura fundiária do Estado, baseada em colônias agrícolas étnicas ou, então, nas grandes propriedades e na monocultura, a carência de terras disponíveis a baixos preços e os parcos recursos financeiros trazidos por eles inviabilizaram sua fixação no meio rural. Como esses imigrantes também não se enquadraram na categoria de operários urbanos, ficaram à margem do perfil idealizado pela política imigratória brasileira. Assim, eles se concentraram nos centros urbanos, neles desenvolvendo atividades relacionadas ao comércio ou, primeiramente, atuando como ambulantes (mascates) e, mais tarde, em negócios regularmente estabelecidos. Contudo, suas atuações profissionais não estavam restritas somente às cidades, uma vez que a população rural representava um importante contingente de consumidores a serem atendidos (ALMEIDA, 2000, p. 87).

No fim do século XIX e início do XX, no contexto das grandes movimentações de imigrantes que cruzavam o Atlântico em direção as Américas, havia uma preocupação crescente do governo brasileiro em importar agricultores europeus em um claro esforço de "embranquecer" a população. De acordo com Lesser (2001), os imigrantes provenientes do Oriente Médio desafiaram a concepção simplista de raça, acrescentando à 
mistura um elemento novo: a etnicidade. Todos os 4,55 milhões de imigrantes que entraram no Brasil entre 1872 e 1949, trouxeram consigo uma cultura pré-imigratória e criaram novas identidades étnicas; entretanto, foram os 400 mil asiáticos árabes e judeus, considerados não brancos, não pretos, que puseram em xeque as ideias das elites sobre a identidade nacional (LESSER, 2001).

É importante destacar que o binômio sírio-libanês é uma forma hifenizada, negociada entre essas etnias para representar uma categoria, uma ideia ou uma simplificação. Foi uma resposta à indefinição de suas identidades e ao estigma de "turco" (PINTO, 2010). O sírio-libanês, em suma, é o imigrante levantino que chegou ao Brasil a partir das últimas décadas do século XIX, e que, por volta de 1926, passou a ser contado (nos registros de entradas) separadamente como sírio ou como libanês. O binômio também se refere a uma certa igualdade entre o que significa ser sírio, com aquilo que é libanês. Não obstante, existem muitos fatores de aproximação e distanciamento entre essas etnias. Os de aproximação estão na língua, cultura e alimentação, e entre os de distanciamento estão, de forma geral, o conservadorismo dos sírios em contraste com a sociabilidade dos libaneses, além de fatores confessionais como o maronismo ${ }^{1}$, exclusivo dos libaneses cristãos.

O libanês na sua origem, a rigor, é mais cosmopolita e ocidentalizado por causa da influência francesa, especialmente àqueles provenientes do Monte Líbano $^{2}$. O sírio cristão, por fazer parte de uma minoria étnica na origem, sentia-se oprimido pela maioria muçulmana e chegou ao Brasil com este trauma, ao passo que o libanês, em geral, sem sofrer tanto pelo mesmo motivo, foi mais impactado pelo fator econômico na decisão de emigrar. O termo sírio-libanês é usado para substituir a expressão "imigrante árabe" no Brasil, na Argentina e no Uruguai (PINTO, 2010).

Historicamente, a Palestina, a Síria e o Líbano sempre guardaram laços sociais profundos, e suas fronteiras foram desenhadas pelos invasores que os dominaram politicamente. O idioma, a cultura, as religiões e muito da culinária, apesar de pequenas diferenças, aproximam ainda mais a Palestina da Síria e do Líbano. Por fim, cabe ressaltar que grande parte dos descendentes desses imigrantes são filhos de pessoas das duas origens: síria e libanesa. Eles são os filhos dos imigrantes que, naquela ocasião, faziam questão que seus filhos se casassem com outros sírios, ou libaneses, dentro da pequena colônia gaúcha de imigrantes árabes de então.

Oobjetivodeste estudoémostraros contrastes entre as primeiras posições desses imigrantes na cidade de Porto Alegre, tanto de libaneses quanto de sírios, inicialmente em condições precárias, para depois de alguns anos, realizando investimentos conjuntos no ramo do comércio, lograram através deste meio uma notável ascensão social e mobilidade espacial, refletida na ocupação de diferentes bairros da capital mas também na educação formal de seus filhos, principalmente nas melhores escolas da cidade. Neste artigo, descrevemos a trajetória de inserção e integração desses imigrantes e como eles foram capazes de transformar suas realidades. A novidade que trazemos é o método da pesquisa para mostrar o que pretendemos. Realizamos desde investigações em fontes primárias como os arquivos históricos, reportagens de jornais da época, literatura memorialista e entrevistas com descendentes de imigrantes.

\section{Rua Andrade Neves: Gueto Étnico ou a pequena Síria de Porto Alegre?}

No início do século $\mathrm{XX}$, quando os imigrantes sírios e libaneses já circulavam pela capital em maior número, seu núcleo residencial e comercial era a rua Andrade Neves', no centro histórico da capital ${ }^{4}$. Porto Alegre começou a receber imigrantes sírios e libaneses em maior quantidade a partir de 1890, conforme verificamos nas crônicas e no comércio local. Comerciantes mais antigos ${ }^{5}$ recebiam mercadorias no porto da cidade, vindas de São Paulo ou do Prata, e repassavam aos mascates, que as vendiam pelo interior.

O padrão de ocupação e concentração não era diferente do de outras capitais ou cidades brasileiras, como a rua 25 de Março, em São Paulo, ou a rua da Alfândega, no Rio de Janeiro. Nessa época, a maioria dos árabes eram mascates e saíam, a pé ou de carroça, vendendo frutas, legumes e miudezas pelos arrabaldes da cidade e outros municípios do estado, onde recebiam pedidos de mercadorias. Eles voltavam ao mercado da capital para adquirir os produtos e tornavam a viajar levando as encomendas. Corbinos (1983, p. 82) 
descreve assim seus locais de residência: "Viviam inicialmente em cortiços, moradias populares com cômodos para alugar, onde se aglomeravam famílias inteiras em um reduzido espaço". Ainda segundo o autor, era peculiar o comércio praticado em longos trajetos percorridos como vendedores ambulantes de sotaque tão característico ${ }^{6}$.

A presença de sírios e libaneses na capital foi registrada por um viajante alemão que esteve em Porto Alegre em 1904. Hans Ramelow declara, em suas memórias, o que viu na capital:

[os árabes] ocupam-se com predileção do comércio varejista e ambulante, uma vez que parecem especialmente adequados justamente para este tipo de venda de mercadoria. Por sua condição comercial insistente e apregoadora, eles são concorrentes que pouco agradam ao comércio alemão. (NOAL FILHO; FRANCO, 2004, p. 110).

Outro viajante que esteve em Porto Alegre em 1903 também observou a presença desses imigrantes. O alemão Wilhelm Lacman, em suas memórias, descreve assim um passeio pelo centro de Porto Alegre:

A rua dos Andradas é a principal via de circulação de Porto Alegre, repleta de vida colorida. Negros e mestiços com negros de todos os matizes [sic], luso-brasileiros, italianos e alemães misturam-se aqui, uns com os outros. Aqui e ali, também encontramos rostos orientais. Isto porque Porto Alegre possui uma boa quantidade de lojistas sírios, os quais dispõem até de um jornal próprio, redigido em idioma árabe. (NOAL FILHO; FRANCO, 2004, p. 96).

Em nossas pesquisas no Arquivo Púbico do Estado e periódicos da capital gaúcha, procuramos por ocorrências de toda ordem ligadas à rua Andrade Neves. Com efeito, encontramos alguns casos de ocorrências policiais (agressões) e questões de disputa comercial (falências e protestos) que resultaram em queixas-crimes. Nosso intuito aqui não foi a tabulação quantitativa desses casos, mas tão somente ilustrar a ocorrência de fatos do cotidiano envolvendo a comunidade árabe em sua principal área de localização.
Ilustrativo, nesse sentido, foi o caso de Elias Chediac, ocorrido em 1896. Comerciante atacadista de fazendas e miudezas ${ }^{7}$, estabelecido na rua Andrade Neves, $n^{\circ} 56$, Chediac ingressou com uma ação de cobrança, em abril daquele ano, contra seu patrício, $o$ mascate Abdalla Assli, a quem tinha dado um crédito no valor de mais de 250 mil réis, "proveniente de mercadorias que comprou para revender".

Em 1898, dois anos mais tarde, teve lugar um violento acerto de contas na rua Andrade Neves entre dois pequenos comerciantes de duas famílias de origem árabe. Diz-se que tudo foi resolvido com muita gritaria, bofetões e cadeiradas. A violência rapidamente descambou para navalhadas, facadas e até tiros, resultando em quatro feridos, um em estado grave. O jornal Correio do Povo estampou na primeira página de sua edição matinal de 13 de janeiro de 1898 a seguinte manchete em letras garrafais: "GRANDE CONFLICTO". Em letra menor, abaixo, antes do texto da reportagem, lia-se: "Tiros, facadas e prisões".

O repórter do Correio do Povo parecia não ter entendido inteiramente o que havia acontecido entre os árabes da rua Nova, pois na introdução da matéria, assim escreveu a respeito do ocorrido:

A origem do conflito está ignorada, tal o mistério em que a rodeia, quer os implicados no distúrbio, quer os que os testemunham. Um de nossos repórteres, que acompanhou todos os passos da autoridade policial, bem como o curativo dos feridos, tem fundamentos para acreditar que o conflito tenha se motivado por uma questão de 20 libras esterlinas [...] que um dos feridos tentara alapardar. Pelo menos foi isso que, por terceiros, veio a saber o subintendente do $1^{\circ}$ Distrito ${ }^{8}$. (Correio do Povo, 13 jan. 1898, p.1)

O caso se dera, conforme a reportagem do jornal, na manhã do dia 12. A matéria informava que o árabe Abrahão Bushdid, ao chegar de viagem, foi a uma agência de leilões para fazer o pagamento de uma conta, mas ao regressar à rua Silva Lima ${ }^{9}$ foi inesperadamente agredido por um compatriota seu chamado José Fortunato, que lançou na sua direção uma cadeira e, em seguida, puxou uma faca. Dizia ainda a reportagem que a confusão começou 
em frente à residência de Bushdid, situada na rua Andrade Neves, $n^{\circ} 13$. A fim de se defender da agressão, Bushdid correu em volta de uma carreta que estava estacionada em frente à sua casa até que conseguiu entrar no imóvel. A ação continuou com José Fortunato em perseguição a Bushdid no interior da residência. Passados alguns instantes, ouviu-se da rua o disparo de dois tiros. Abrahão Bushdid, em seu depoimento, alegou que não tinha sido ele o autor dos disparos. Continua o jornal:

Daí passou o conflito para a rua envolvendo-se nele Abrahão, José Fortunato, Judith Bushdid e José Francisco, irmã e sogro de Abrahão, e Nassif Antônio, que travaram renhida luta. Feridos, os três primeiros se refugiaram todos no prédio $n^{\circ} 56$, na mesma rua Nova, onde mora até nos porões, em repugnante promiscuidade, grande quantidade de homens, mulheres e crianças. (Correio do Povo, 13 jan. 1898, p. 1).

Ainda segundo a reportagem, Abrahão foi ferido no braço por golpes de navalha; Judith levou duas facadas. Já Fortunato recebeu dois ferimentos à bala, e seu estado foi considerado grave. Os três feridos foram mandados se recolher à enfermaria da cadeia civil para ficarem à disposição da Justiça (Correio do Povo, 13 jan. 1898, p. 1). O que se conclui depois da análise do tipo de discurso veiculado pela reportagem do Correio do Povo é que o que foi publicado reflete e reproduz em grande medida o pensamento da época, influenciado por valores positivistas que sugerem ser aquele grupo, formado por pessoas de uma determinada minoria étnica, agente de práticas socialmente reprováveis, no contexto de uma cidade que começava a se enxergar como uma metrópole moderna e civilizada.

Acompanhando o crescimento da cidade, a rua Andrade Neves continuou a receber árabes em busca de dias melhores e bons negócios. Assim, localizamos em setembro de 1902, no Arquivo Público Estadual, um processo de cobrança judicial proposto por Jorge Monaiar (APERS, 1902) contra Simão João Curi, ambos "sírios" e negociantes. Proprietário da Jorge Monaiar \& Cia. ingressou com uma ação cobrando de Simão o valor de 394 mil e 210 réis em mercadorias, cujas compras haviam sido feitas por ele a prazo, em fevereiro de 1901, e estavam sem quitação havia mais de um ano e meio.
Em outro processo (APERS, 1903), este da área criminal, datado de 7 de abril de 1903, encontramos novamente o nome do comerciante Jorge Monaiar. Desta vez, o processo tramitava como uma queixa-crime de Jorge contra o negociante Miguel Curi. O escrivão relata que “[...] no dia 2 de abril, pelas $9 \mathrm{~h}$ da noite daquele mesmo dia, Jorge foi procurado insistentemente por Miguel Curi, domiciliado nesta cidade e natural da Síria, em diferentes lugares, com o fim de com ele [sic] entender-se". A narrativa do queixoso continua fazendo constar, nos autos, a maneira sorrateira como agiu seu patrício:

Achando-se a vítima de visita à casa número 34 da rua Andrade Neves, lá foi ter com o réu, que, lhe pedindo cordialmente uma palavra, fez com que o suplicante o acompanhasse até a rua. Dados, porém, alguns passos ao lado um do outro, o réu, inopinadamente, agrediu fisicamente o queixoso e, derrubando-o ao chão, em seguida lançou mão de uma faca que trazia na cintura diligenciando matá-lo, o que não conseguiu devido à intervenção de diversas pessoas que acudiram com toda presteza e conseguiram deter $\mathrm{o}$ réu que, em altos brados, protestava matar o mesmo queixoso, e nessa ocasião proferiu em árabe a maior das exclamações injuriosas e ameaçadoras, qual seja: "Hei de queimar tua fé." (APERS, 1903).

Revela a queixa que aquelas mesmas pessoas que acudiram Jorge, "impedindo sua morte", chamaram a polícia, visto que, nesse meio tempo, o agressor conseguiu evadir-se do local, frustrando a prisão em flagrante. Contudo, continua a denúncia: "No dia seguinte, o mesmo réu andou rondando a casa da vítima, mas então armado de um revólver, fato este que demonstra que ele ainda está no mesmo desígnio de consumir o assassinato do queixoso" (APERS, 1903). Tendo acusado formalmente Miguel Curi à Promotoria Pública, o advogado de Jorge Monair solicitou que se mandasse citar o acusado para que este respondesse de acordo com base nos artigos do Código Penal referentes ao tipo de crime que lhe era imputado.

Depois de apresentar seu rol de testemunhas, o advogado por fim requeria uma indenização à vítima no valor de 10 contos de réis. "Entre as 
oito pessoas arroladas como testemunhas, todas elas 'patrícios' da rua Andrade Neves, um nome em especial chamou nossa atenção: Dr. Jorge $\mathrm{H}$. Naamann, "um médico sírio, nascido em Beirute!" (MOELECKE, 2013, [s. p.]). Não é possível saber se Dr. Naaman exercia ali simplesmente a sua obrigação profissional, prestando assistência aos doentes, ou se também aplicava as regras mais modernas de boa saúde e higiene que aprendera na "Universidade de Medicina de Paris ${ }^{10 "}$. O fato é que Dr. Naaman acabou se aliando a um dos lados do conflito, o que inevitavelmente terminou por legitimar um frente ao outro.

Diante do exposto, podemos tecer as seguintes considerações: em primeiro lugar, o fato revela de que esses árabes foram violentos $\mathrm{e}$ brigaram entre si na rua Andrade Neves talvez por não estarem totalmente integrados aos costumes "civilizados" da cidade, que utiliza os meios legais para encaminhar suas diferenças. Não chega, portanto, a configurar uma surpresa que pessoas provenientes de outro universo sociocultural, não citadino, resolvessem suas desavenças com sangue, uma vez que a honra pessoal e a fidelidade para com a família costumavam ser mais importantes do que as relações estabelecidas por estes indivíduos com as instituições do Estado, incluindo a própria lei (LESSER, 2001).

\section{Distribuição espacial de sírios e de libaneses em Porto Alegre}

Localizamos no levantamento que realizamos nos arquivos históricos de Porto Alegre, nas primeiras décadas do século XX, muitas famílias de sírios e de libaneses residentes nos bairros próximos ao Centro, como Floresta e Cidade Baixa, mas também em bairros operários do $4^{\circ}$ Distrito da capital $^{11}$, como São João, São Geraldo e Navegantes, conforme veremos a seguir. Porém, em relação à época sobre a qual escrevemos, a maioria dos imigrantes árabes ainda preferia os cortiços do Centro por medida de economia, mas principalmente porque não podiam abrir mão de estar presentes no coração da cidade, uma vez que era ali que se concentrava o grosso do comércio e também maior densidade de pessoas circulando, o que somente se intensificou à medida que o século XX foi avançando.
Schilling (2007, p. 35) nos traz a informação que corrobora com a expansão da cidade para fora do Centro em direção aos bairros mais afastados, onde o Poder Público havia preparado uma pequena infraestrutura e incentivado a aquisição de lotes, que os irmãos Felippe e Chain Selaimen, “[...] compraram, em 1914, uma área no bairro São João, $4^{\circ}$ Distrito de Porto Alegre, para explorar uma pedreira". Porém, conforme narra a autora, que em 2006 entrevistou os mais velhos da colônia, com o fracasso do empreendimento, os irmãos lotearam o terreno em 1925, atraindo para o local muitos imigrantes que pouco a pouco foram construindo suas próprias moradias. Segundo Schilling (2007), com a vinda dos primeiros libaneses, outros mais que estavam residindo no Centro e em outros pontos da cidade começaram a fluir para o bairro de São João. Essas informações encontram apoio em uma passagem de Pesavento (1994, p. 43) que afirma existirem, na última década do século XIX, fatores como aumento das taxas prediais no Centro que "[...] elevaram substancialmente o valor dos aluguéis, forçando a migração desses grupos para lugares mais afastados, com moradias mais baratas, que constituíam os bairros operários-fabris de Navegantes e São João".

$\mathrm{Na}$ pesquisa que fizemos em 2015 no Arquivo Nacional, referentes aos anos de 1939 a $1949^{12}$, levantamos 753 nomes de sírios e de libaneses que se cadastraram nos escritórios da Polícia Federal do Estado do Rio Grande do Sul, vimos que 436 residiam em Porto Alegre, ou seja, $58 \%$ do total de imigrantes do estado.

Do conjunto desses residentes, 146 se fixaram no Centro, ou seja, por volta de $33 \%$. A região central da cidade concentrava, então, duas vezes mais sírios do que o bairro vizinho (Floresta), onde contamos 55 pessoas. Provavelmente essa concentração de árabes nos bairros Centro e Floresta devia-se ao fato de esses imigrantes preferirem residir em seus próprios locais de comércio. Os bairros da cidade que na época pesquisada contavam com imigrantes árabes, conforme ilustra o gráfico a seguir, eram os seguintes: 


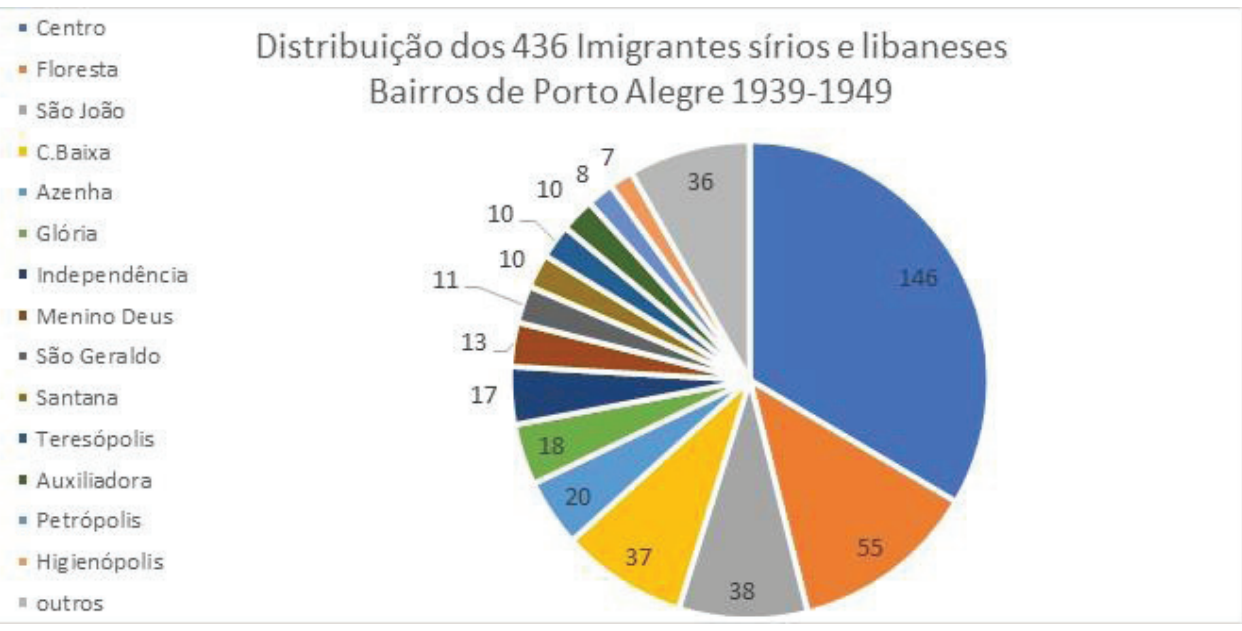

Gráfico 1: Distribuição de imigrantes sírios e libaneses por bairros de Porto Alegre (1939 1949) Fonte: Adaptado de dados colhidos no Arquivo Nacional do Rio de Janeiro (2015).

É importante pontuar que, na época em que os dados foram colhidos, a maioria dos bairros listados eram servidos por bondes elétricos e, também, por importantes artérias viárias que ligavam aqueles ao Centro. As localidades mais populares ou operárias eram os bairros Floresta, São João, Cidade Baixa, Azenha, São Geraldo, Higienópolis e Glória. Os emergentes eram Santana; Petrópolis; Teresópolis e Auxiliadora, e aqueles mais sofisticados com aluguéis e terrenos mais caros eram Independência, Moinhos de Vento e Menino Deus. O centro da Cidade ainda representava um local difícil de viver para quem era trabalhador assalariado, pequeno comerciante ou operário. Segundo Franco (1988) e Pesavento (1994), naquela época, o centro de Porto Alegre representava um padrão de vida açodado, pois era densamente povoado e sem saneamento básico na maioria das residências, quando muitas que abrigavam imigrantes urbanos eram pensões e "cabeças de porco"13. As obras de modernização do centro da Capital, na década de 1940, com alargamento de avenidas e a construção de equipamentos urbanos, como viadutos e praças coincidiu com mais um impulso da já conhecida política pública, iniciada no início do século XX, para atrair os mais pobres para fora do centro, quando foram abertos novos loteamentos na Zona Sul da Cidade e ampliada a malha viária da cidade.
O mapa a seguir (Figura 1) ilustra a concentração desses imigrantes nos bairros de Porto Alegre na década de 1940 (ARQUIVO NACIONAL, 1939-1949). De acordo com os endereços que constam nas fichas cadastrais do Arquivo Nacional, muitos imigrantes sírios e libaneses continuavam residindo nos mesmos locais onde funcionavam os seus comércios, que eram geralmente sobrados em cujo primeiro piso funcionava normalmente o armazém, reservando-se o andar superior ou os fundos da casa, quando o imóvel tinha apenas um pavimento, para a residência da família.

Cabral (1996) vê esse tipo de arranjo como consequência do desenvolvimento capitalista, que havia provocado um aumento populacional "sem precedentes" nas cidades. A autora o descreve como "rua comercial", muito em voga no final do século XIX. De acordo com ela, "[...] a rua comercial inclui o espaço público e necessariamente se limita com esse, quer seja resolvido como espaço unicamente para pedestre, quer como espaço destinado a pedestres e veículos" (CABRAL, 1996, p. 45).

Nesse sentido, o mapa não reflete com exatidão os que moravam em outros bairros $\mathrm{e}$ trabalhavam no Centro da cidade, tampouco aqueles cujos comércios e locais de residência se confundiam no mesmo espaço. O que o mapa acusa, com nitidez, é a presença árabe de uma forma geral gravitando em torno do Centro de Porto Alegre na época aludida. 


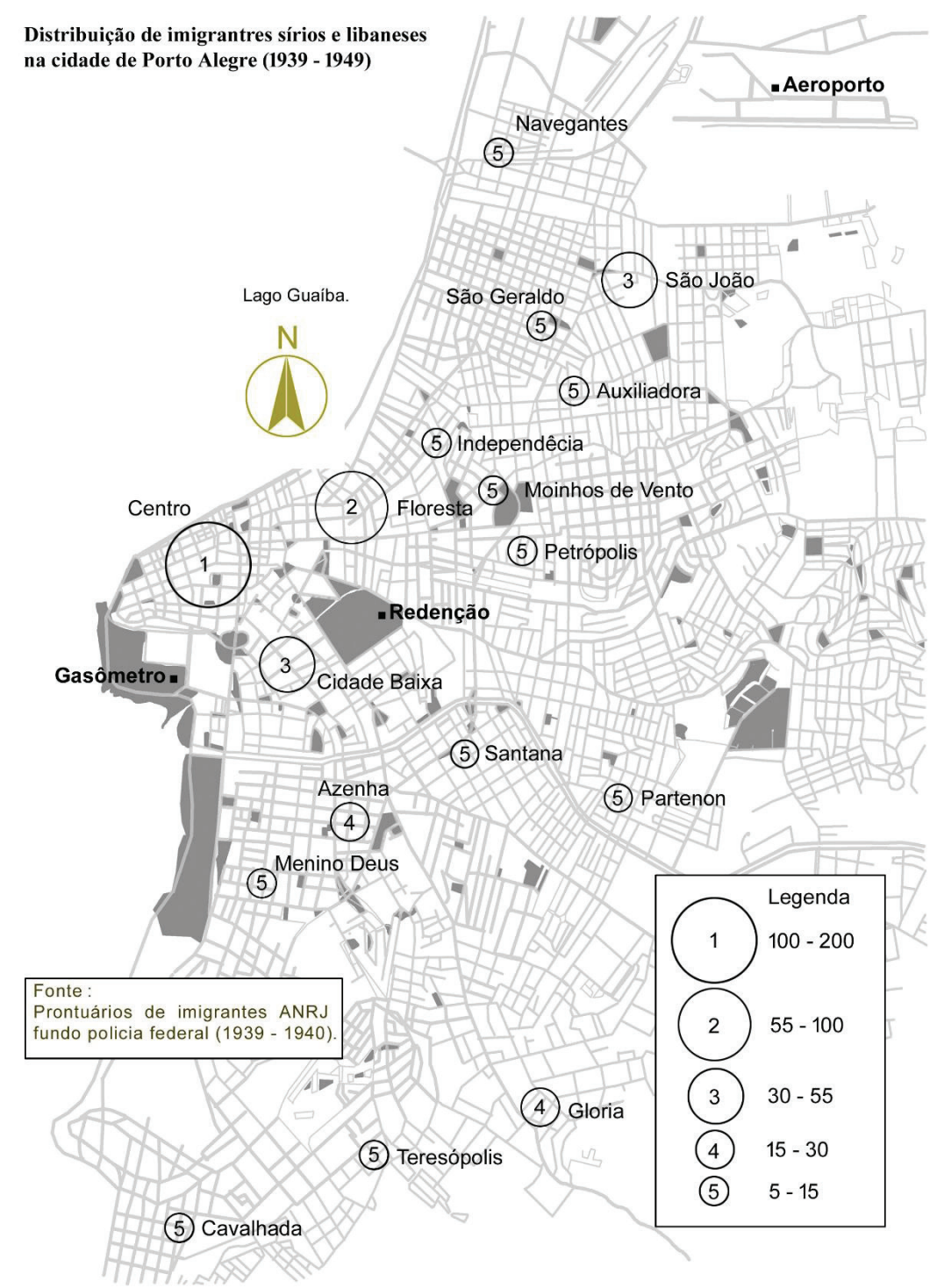

Figura 1: Distribuição de Imigrantes Sírios e Libaneses na cidade de Porto Alegre (1939-1940)

Fonte: Elaborado pelo autor a partir dos dados do ANRJ.

Assim, merecem destaque, pela concentração de sírios, além da região central, os bairros de Floresta e Cidade Baixa, ambos vizinhos ao Centro, e São João, este mais afastado. Em seguida, vinham os bairros servidos por transporte público, como os da Azenha, Glória, Teresópolis e Menino Deus, e os localizados no entorno ou próximos à rua Voluntários da Pátria, como São Geraldo, Navegantes e Auxiliadora. Em números mais modestos, também se verificava a presença da comunidade levantina em bairros como Parthenon, Santana e Petrópolis e nos mais distantes como os de Cavalhada e Tristeza. É certo, contudo, que os terrenos mais baratos foram atraindo, pouco a pouco, uma camada menos favorecida em busca de moradia.
A presença de imigrantes sírio-libaneses também é visível em bairros de aluguéis mais caros, como Moinhos de Vento, Independência e Menino Deus. Fica muito difícil precisar, contudo, em uma cidade como Porto Alegre, o padrão de vida em bairros como Glória, Petrópolis e Auxiliadora, somente para citar alguns exemplos, que poderiam ser bastante aprazíveis na época, apesar de estarem fora do circuito tradicional dos bairros mais sofisticados. Truzzi (1999, p. 334) lembra que os "[...] diferentes locais de moradia, na mesma cidade, dos membros da colônia, talvez tenham se constituído nos primeiros indícios mais claros de diferenciação" entre eles.

Em resumo, verificou-se a presença levantina maciçamente no Centro e nas ruas 
próximas a este. No entanto, as vias de ligação entre um bairro e outro, geralmente atravessadas por artérias importantes da urbe, também eram locais onde esses imigrantes podiam ser facilmente encontrados. Esse era o caso, por exemplo, das ruas Benjamin Constant, que liga os bairros de Floresta e São João, e a avenida João Pessoa, que liga o Centro aos bairros de Menino Deus e Parthenon. $\mathrm{Na}$ Cidade Baixa, como vimos, estão as ruas Sarmento Leite e Lima e Silva, ambas também com forte presença de imigrantes árabes. Uma outra rua onde encontramos uma pequena concentração desses imigrantes foi a rua da Azenha ${ }^{15}$, que ainda hoje dispõe de um comércio popular importante fora do Centro. Outra exceção é a avenida Cascata, localizada em zona menos urbanizada na época, mas que, curiosamente, foi onde se fixou um pequeno, mas significativo número de árabes ali residentes. É importante afirmar que estes últimos casos fogem à regra observada em outras regiões da cidade. $\mathrm{O}$ quadro abaixo mapeia a presença árabe no bairro da Glória, onde fica a avenida Cascata, a rua Nunes, a rua Dr. Rocco e a rua D. João VI. (todos os endereços bem perto uns dos outros).

$\mathrm{O}$ quadro 1 mapeia a presença árabe, especialmente síria, no bairro da Glória, onde fica a avenida Cascata, a rua Nunes, a rua Dr. Rocco e a rua D. João VI. (todos os endereços bem perto uns dos outros).

Quadro 1: Moradores da avenida Cascata e adjacências em Porto Alegre (década de 1940)

\begin{tabular}{|l|c|c|c|c|c|c|c|c|}
\hline Nome & Ano de Nasc. & Profissão & País & Endereço & Chegada & idade & status & Cadastro \\
\hline Seade, Ant & 1897 & sapateir & Síria & Dr. Rocco, 65 & 1911 & 15 & solteiro & 1941 \\
\hline Seade, José & 1886 & comerc. & Síria & Av. Cascata, 2.165 & 1912 & 16 & casado & 1941 \\
\hline Seade, Jabour & 1884 & comerc. & Síria & Av. Cascata, 2.247 & 1904 & 20 & casado & 1942 \\
\hline Esber, Tamer & 1863 & comerc. & Síria & Av. Cascata, 2.229 & 1937 & 74 & viúvo & 1944 \\
\hline Isse, Antônio & 1887 & comerc. & Síria & Av. Cascata, 2.227 & 1907 & 20 & casado & 1945 \\
\hline Isse, Maria & 1899 & domest. & Síria & Av. Cascata, 2.227 & 1905 & 16 & casada & 1945 \\
\hline Abech, Amiz & 1893 & - & Síria & Av. Cascata, 2.227 & 1908 & 15 & - & 1943 \\
\hline Basra, Gattas & 1878 & comerc. & Síria & Av. Cascata, 2.319 & 1902 & 24 & - & 1946 \\
\hline Ceccin, Rosa & - & domest. & Síria & Av. Cascata, 2.671 & - & - & viúva & 1941 \\
\hline Kalil, Miguel & 1888 & comerc. & Líbano & Av. Cascata, 2.994 & 1907 & 18 & casado & 1943 \\
\hline Kalil, Josefa & 1889 & domest. & Líbano & Av. Cascata, 2.994 & 1904 & 16 & casada & 1943 \\
\hline Zaquia, Jorge & 1886 & ambula. & Síria & R. Nunes, 294 & 1907 & 21 & casado & 1940 \\
\hline Cure, Ramon & 1898 & ambula. & Síria & Av. Cascata,3.187 & 1924 & 26 & casado & 1939 \\
\hline Slim, Ibrahim & 1888 & comerc. & Síria & D.João VI, 103. & 1907 & 19 & solteiro & 1940 \\
\hline Dumet, José & 1887 & operário & Síria & D.João VI, 111. & 1903 & 19 & casado & 1940 \\
\hline Salamoni, Maria & 1876 & domest. & Síria & D. João VI, 69. & 1914 & 38 & solteira & - \\
\hline Abech, Rachid & 1888 & - & - & D. João VI, 84. & 1908 & 20 & & - \\
\hline
\end{tabular}

Fonte: Arquivo Nacional. [s.d.].

Analisando o quadro acima percebe-se, em primeiro lugar, que a maioria desses imigrantes é de sírios, muitos de uma geração nascida no último decênio do século XIX e que emigrou para Porto Alegre nas primeiras décadas do século XX. A exemplo do que aconteceu com o bairro de São João na segunda década do século XX, atraindo especialmente os libaneses para um loteamento naquele lugar, os dados apontam para um movimento de mobilidade conjunto de sírios na década seguinte evidenciando que, para alguns deles, um lote na Glória, onde está localizada a avenida Cascata, e as citadas ruas adjacentes, significou uma opção acessível ao Centro da cidade, já saturado.

Talvez seja possível levantar algumas hipóteses acerca da origem desses deslocamentos a partir de uma lógica de distribuição espacial também relacionada a fatores não propriamente econômicos, como a existência de redes familiares que aglutinassem grupos em determinadas regiões, através da compra conjunta de terrenos em loteamentos. É possível observar que esses árabes se fixaram nesses locais desde o início da década de $1920^{16}$, antecipando-se a grupos mais numerosos e provavelmente conseguindo melhores preços nessas áreas, uma vez que, de acordo com Franco 
(1992), o povoamento dessas regiões se acelerou a partir da década de 1950, graças à abertura de novos acessos, à expansão dos meios de transporte e ao loteamento das encostas dos morros da Polícia (também chamado Glória) e Cascata. Tanto para o bairro operário de São João, quanto para as zonas mais bucólicas da Glória ${ }^{17}$, a distância geográfica não era um obstáculo, pois, como vimos, já havia um sistema de bondes em Porto Alegre desde o fim do século XIX. Além disso, com a chegada de novos moradores a partir da década de 1950, o exercício da atividade comercial se viabilizou nos próprios bairros de residência desses imigrantes.

\section{Educação e ascensão social}

Diversos autores (KNOWLTON, 1960; HAJJAR, 1985; LESSER, 1992; TRUZZI, 1997; PINTO, 2010) têm como ponto pacífico que grande parte da colônia sírio-libanesa dava importância suprema à educação formal de seus filhos, e, dependendo da classe social e do nível de acumulação de seus integrantes, o objetivo sempre foi colocá-los em escolas de primeira linha. Truzzi (1999, p. 351) indaga se não foi este, afinal, o caminho que levou "à prova de fogo" da assim chamada integração: "o momento em que filhos de patrícios disputaram ombro a ombro posições de prestígio antes reservadas às elites, tanto no sistema educacional [...]., quanto posteriormente no mercado de profissões liberais." Assim, os descendentes de imigrantes, principalmente aqueles matriculados nas escolas mais caras da capital, representaram para a comunidade levantina um passo à frente em seu caminho da integração à sociedade gaúcha em uma esfera mais alta, uma vez que era ali que os filhos das elites daquela sociedade se encontravam.

Embora as fontes que apresentaremos a seguir sejam de escolas particulares e as mais caras de Porto Alegre, algumas exclusivas para rapazes, como a antiga Escola dos Padres (Ginásio Anchieta) e o Colégio do Rosário, elas são representativas e servem para ilustrar o processo descrito no parágrafo anterior ${ }^{18}$.

O Colégio Anchieta, de Porto Alegre, por exemplo, é a única instituição de ensino do fim do século XIX que guarda registros daquela época. $\mathrm{O}$ Colégio do Rosário, também da capital, embora só tenha começado a arquivar seus registros em 1930, com a publicação da Revista Ecos, também representa tradição de ensino para a elite gaúcha, sendo que - e isso é importante frisar - foi de dentro dessa instituição que surgiu a primeira universidade católica privada, que passou a fazer um contraponto com as instituições estatais que emergiam na época.

Neste sentido, investigamos primeiramente, para as primeiras décadas do século $\mathrm{XX}$, os alunos de ascendência síria e/ou libanesa matriculados no Colégio Anchieta ${ }^{19}$. A instituição situava-se no Centro de Porto Alegre, à rua Duque de Caxias, n.295, próximo de onde hoje fica o Museu Júlio de Castilhos.

Entre os 299 alunos matriculados em 1916, havia apenas um descendente de árabe ${ }^{20}$ : Antônio Assad Chemale, que cursava a $2^{\text {a }}$ série preliminar. No ano seguinte, encontramos o nome de Waldemar Assmus, que prosseguia matriculado em 1919. Neste último ano, o Colégio ganhou um outro pavilhão, aumentando a capacidade e estrutura, que passou a funcionar com cerca de 500 alunos permanentes. Em 1920, apareceu o nome do aluno Jorge Maluf, matriculado no $1^{\circ}$ ano do Ensino Médio e que no final do ano letivo recebeu uma menção honrosa por ter tirado a $15^{\mathrm{a}}$ melhor nota final. Em 1921, os registros do Colégio apresentam mais um descendente de árabe: Moacyr Simon, matriculado nas séries elementares. No ano de 1922, conquistando menção honrosa pelo conjunto da obra, juntava-se aos nomes sírios Ignácio Amim, matriculado no $3^{\circ}$ ano elementar. Em 192321, localizamos Antônio Allem, do $1^{\circ}$ ano elementar. Em 1924, Moacyr João Simon, do $1^{\circ}$ ginasial, agraciado com um prêmio de honra, e Jorge Maluf, do $6^{\circ}$ ano ginasial, que recebeu prêmio de aproveitamento. Além dos dois laureados, Antônio Allem completava o time de 'patrícios'.

Em 1926, o número de descendentes de sírios saltou para 11 alunos $^{22}$. O primeiro colocado entre eles foi Antônio Saffi, menção honrosa em caligrafia, história do Brasil e português, com 785 pontos $^{23}$. Além dos nomes citados, ainda verificamos as presenças de Farid Zogbi, Alfredo Emílio Allem, Orlando Aidar, Kalil Miguel Kalil, Victor Jorge Simões, Fortunato Elias Kalil e Moacyr João Simon ${ }^{24}$. Em 1927, com 12 nomes sírios ou libaneses, a menção honrosa foi para Nesralla Abraão, do $3^{\circ}$ ginasial, pelo conjunto da obra. Neste ano também se destacaram Chaphick Saadi e Haide Elias Aesse. 
Em 1928, a instituição foi estadualizada, mesmo ano em que o filho de patrícios Haid Elias Aesse ganhou o prêmio de excelência, $1^{\circ}$ lugar do curso preliminar. Nos últimos anos da década de 1920, com a abertura do curso noturno, os alunos de ascendência sírio-libanesa do Colégio Anchieta eram contados em número de 23 pessoas.

Em 1930 e 1931, ainda em decorrência dos efeitos da crise mundial de 1929, este número estabilizou-se em 12 alunos. Novos nomes de descendentes, como Jorge Creidy, Miguel Kanaan,
François Nehmé, Ely Eluf, João Dirani Rechden e Jorge Elias Thomaz abriram a década de 1930; porém, desta data em diante outros bons colégios da cidade, públicos e privados, começaram a fazer concorrência ao Anchieta. A miscigenação dos descendentes com outras etnias tornou a continuação da pesquisa inviável, principalmente após a década de 1940.

O gráfico a seguir ilustra a evolução do número de alunos de origem sírio-libanesa matriculados no Ginásio Anchieta entre os anos de 1916 e 1931:

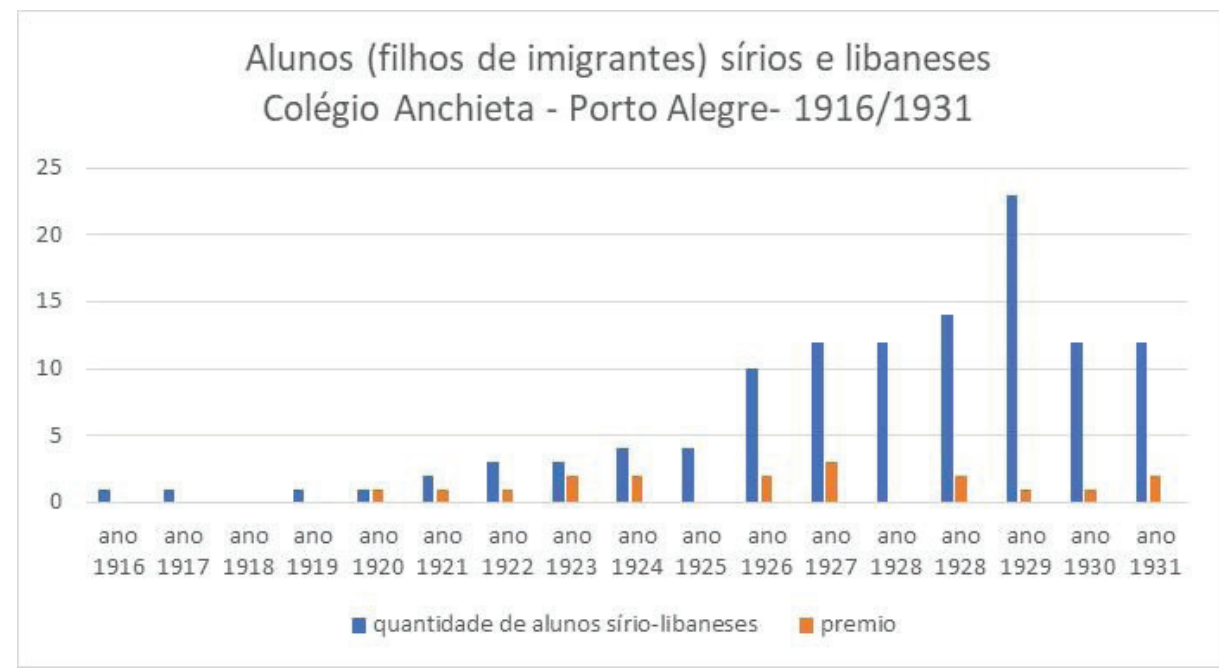

Gráfico 2: Alunos (filhos de imigrantes) sírios e libaneses. Colégio Anchieta. Porto Alegre (1916-1931)

Fonte: Colégio Anchieta. [s.d.].

Quanto ao Colégio do Rosário ${ }^{25}$, a instituição iniciou suas atividades no Centro de Porto Alegre, onde, junto a uma Igreja, começou a funcionar em 1904. Em 1927, os Irmãos Maristas, mantenedores do Colégio, transferiram sua sede para um amplo terreno no bairro da Independência, bem próximo ao Centro, onde a instituição está localizada até hoje.

Em 1930, data em que a escola iniciou seu arquivo histórico, já contava com quase 1.000 alunos. Neste ano, havia 12 alunos com nomes árabes matriculados na instituição, entre eles alguns oriundos de famílias de Porto Alegre, como Eugênio Selaimen, José Chemale, Líbano Buchabique, Jorge Maluf e Elias Saadi, e outros de Rio Grande, como Alziro Salim Sessim e Jorge Feres. Frequentavam ainda a instituição os jovens da família Dibe, (Sabre e Invar), o primeiro tendo sido laureado como destaque de excelência daquele ano. Os alunos representantes das famílias que se estabeleceram em regiões de colônia eram Eduardo José Koff, Jorge Nelson Elias; Egídio Sequef e Danilo Davi.

Verificando a mesma fonte uma década depois, ou seja, em 1940, observamos semelhante média de alunos de origem árabe matriculados no Rosário, assim como a mesma distribuição desses alunos segundo a origem de suas famílias no estado. Em 1940, os representantes das famílias da capital eram José Buchabique, Nelson Allen e Adão Elias; do litoral e região sul do estado, Harry Cheuiche e Antônio Sessin Gil; e da Serra Gaúcha, os estudantes Rames Koff Nehmé e Henrique Zacher ${ }^{26}$.

$\mathrm{O}$ ingresso dos descendentes de imigrantes sírios e libaneses nas escolas da elite forneceu uma experiência de grupo, um antecedente intelectual comum entre o filho de imigrante e outros moços das camadas mais selecionadas da população. E também a primeira oportunidade, fora da família alargada, para que aqueles estabelecessem redes de amigos que em 
muitos casos depois se revelariam úteis socialmente no desenvolvimento de suas carreiras.

Conforme observa Logroño-Narbona (2007, p. 190), as escolas mais caras eram uma espécie de laboratório que treinava os meninos e os jovens para serem homens da elite. "Ali eles foram socializados para se adequarem ao modo de vida da classe dirigente, para ocupar os cargos nas instituições formais do Estado - o partido político, a burocracia superior, os bancos, o corpo diplomático" [...].

Em 2014, nós entrevistamos um descendente de imigrantes libaneses octogenário muito conhecido entre os sócios da Sociedade Libanesa e os descendentes de libaneses do bairro de São João. Apenas para fazer um contraponto e não esquecer que nem todos eram ricos, ele nos relatou, de forma dramática, que seu pai era pobre e não podia pagar pela educação de todos os filhos. $\mathrm{O}$ entrevistado, que pediu para não ter seu nome revelado, caiu em prantos à nossa frente, quando lembrou as dificuldades que o pai enfrentou:

Depois do ensino fundamental, que era público, meu pai não podia sustentar a casa e manter todos os filhos na escola, que era particular. Eu, como era o mais velho, percebi sua aflição e pedi para sair do colégio para ajudá-lo na loja [de molduras e vidros para quadros e fotografias]. Hoje sou um dos únicos que não têm nível superior, mas possuo uma boa casa própria, apartamento na praia e formei todos os filhos.

Já outro entrevistado, Rafique João (2015, [s. p.]), nos conta que "não estudou porque não quis". Para seus pais, entretanto, a maior satisfação de suas vidas era ver formados os filhos no Ensino Médio, como fez seu irmão mais velho, que se formou como técnico de contabilidade: "A mãe ficava tão feliz vendo os filhos formados, e mandava emoldurar os diplomas para colocá-los expostos nas paredes da sala de casa", completou Rafique.

Truzzi (1997) afirma que a proporção de filhos de sírios ingressando no ensino superior foi bem maior quando comparada com a de outras etnias. $\mathrm{O}$ autor explica o fato pela rápida ascensão econômica desses imigrantes, a qual foi propiciada pela cadeia que vai de mascate a comerciante e atacadista em um período relativamente curto de tempo. O entrevistado Mohamed Baccar (2003, [s. p.]). nos falou de sua experiência:

Meu pai pagou, na época, os melhores colégios de Porto Alegre. Me mandou para Porto Alegre estudar. Estudei no Colégio IPA. Que era um colégio caro na época. No IPA não tinha científico na escola. Na época minha mãe chorou muito porque queria que eu tirasse economia lá, economia não, guarda livros, mas ele não, ele disse que queria que eu tirasse faculdade. Então eu tinha que fazer cientifico em Porto Alegre. Então eu fiz científico. Eu era interno. Voltava para casa em cada Carnaval, Natal, essas coisas assim.

A imigração sírio-libanesa no Rio Grande do Sul nas primeiras décadas do século XX revelou simultaneamente facetas diversas. De fato, enquanto alguns descendentes estudavam, inclusive entrando nos cursos superiores ${ }^{27}$, outros jovens imigrantes chegavam ao Brasil, igualmente no início de suas jornadas, e começavam suas trajetórias de mascate pelo interior, onde não raro se estabeleciam em cidades emergentes pela instalação de novas colônias ou nos distritos menores de cidades médias, depois de alguns anos trabalhando como ambulantes.

\section{A guisa da conclusão}

No início, como vimos, ocorreu uma concentração desses imigrantes em uma espécie de gueto étnico representado pela inóspita rua Andrade Neves. A dedicação em massa a atividades comerciais, com a formação de redes étnicas de cooperação e parentesco, possibilitou ao grupo o abandono do 'gueto' e o deslocamento, algumas vezes em grupo, ocupando loteamentos em áreas populares, porém, menos degradadas da capital. A união desses imigrantes, mesmo os pequenos comerciantes sem muito capital, possibilitou a aquisição de terrenos em zonas afastadas do saturado centro de Porto Alegre como os bairros de São João, na década de 1930 e o da Glória, na década posterior.

Esses imigrantes deram uma importante contribuição ao processo de ocupação do território Rio-grandense, funcionando como elementos dinamizadores dos mercados local e regional, integrando regiões até então isoladas do mercado 
consumidor (NUNES, 1986, p. 62). Nos primeiros anos de atividade, os mascates, em visita às cidades interioranas e principalmente às fazendas, levavam apenas miudezas e bijuterias. Mas, com o passar do tempo e o aumento do capital, começaram também a oferecer tecidos, lençóis, roupas prontas, entre outros artigos. Conforme acumulavam os ganhos, os mascates contratavam um ajudante ou compravam uma carroça; o passo seguinte era estabelecer uma casa comercial. Foram eles que introduziram as práticas da alta rotatividade e da grande quantidade de mercadorias vendidas, das promoções e das liquidações. (TRUZZI, 1997)

Como justifica Jeff Lesser (2001, p. 25), a etnicidade não se refere apenas à cultura social, mas também à cultura econômica. Sob este aspecto da cultura urbana, de acordo com Rosemary Brum (2009, p.170), os imigrantes se encaixam em novas categorias socioeconômicas, nas quais o estrangeiro também é visto como o homem diante da metrópole moderna, que forja uma cultura urbana, onde ele vai tecendo relações e se inserindo na vida política e econômica da sociedade.

Os libaneses e os sírios, em Porto Alegre, passaram de meros figurantes - inseridos em uma espécie de gueto étnico na rua Andrade Neves - a protagonistas ao longo da primeira metade do século XX. Esse processo criou as condições adequadas para que esses imigrantes que habitavam em cortiços e ganhavam a vida como mascates, se inserissem mais profundamente na sociedade gaúcha. Foi através da atividade mercantil, exercida em um ambiente onde muitos eram parentes e se auxiliavam mutuamente que, apesar das crises e situações adversas, eles conseguiram educar seus filhos nas melhores escolas da capital formando uma elite étnica de origem árabe na segunda geração. Assim, a geração posterior à dos imigrantes, que nasceu brasileira, pôde exercer outras atividades que não as do comércio. Na verdade, essa ascensão através dos bancos escolares coincidiu com a carência e a necessidade de pessoas qualificadas para a construção de uma sociedade republicana baseada no trabalho livre, e por isso observamos na segunda metade do século XX uma elite de origem sírio-libanesa qualificada a exercer papeis de protagonismo nas industriais, nas profissões liberais e na política.

\section{Notas}

1 A origem dos maronitas remonta à comunidade fundada por Maron. Em Antióquia e Alexandria, falavase da natureza divina ou humana de Cristo. Foi, porém, o patriarca Nestor, de Constantinopla, que em 428 estabeleceu a heresia de um Jesus que não era filho de Maria e do Espírito Santo, o que foi combatido por Roma, mas acompanhado pelos maronitas do Líbano. Em razão de sua confissão cristã, os maronitas foram, desde muito cedo, vinculados espiritualmente ao Ocidente.

2 Depois dos massacres contra cristãos, em meados do século XIX, foi reconhecida, sob a proteção da França, a autonomia de uma área no interior da atual costa libanesa. Situada entre as montanhas Líbano e Antilíbano, a região ficaria conhecida como Monte Líbano. O Monte Líbano, uma concessão do Império Otomano dentro do seu território colonial, se caracterizava por ser uma região administrativa independente do resto da Síria, e que terminou por viabilizar a presença de instituições francesas na região que não passavam pelo crivo dos turcos. Isso fez aumentar a influência ocidental naquele território, contribuindo para aumentar as divisões e conflitos entre dois sistemas políticos, sociais e religiosos inseridos numa mesma área geográfica.

3 É uma das ruas mais antigas da capital gaúcha, tendo sido inicialmente denominada de Rua Nova, de 1777 até 1869 . No início do século XX, a ruela era o centro da boemia, com seus cabarés e casas de jogos. O clube dos caçadores, um elegante cassino, foi por muitos anos o grande ponto de jogatina do centro. (FRANCO, 1988).

4 O Arquivo Histórico Moysés Vellinho, de Porto Alegre, lista entre os anos de 1899 e 1915, o nome de 34 árabes ali residentes, todos contribuintes (valores variados) do imposto 'valor locatício'. Número muito superior ao de outras ruas da capital que investigamos. Supomos, que alguns já estavam estabelecidos, a maioria, no entanto, deviam ser mascates que além de residentes naquela rua, apanhavam mercadorias nas lojas de seus patrícios e saíam pela cidade para vende-las.

$5 \mathrm{Em}$ alguns processos de cobrança pesquisados entre esses imigrantes do início do século XX, verificados no Arquivo Público do Estado, percebe-se que dois ou três comerciantes, já estabelecidos, repassavam mercadorias aos demais recém-chegados em regime de consignação para venda de forma ambulante (APERS, 1903, 1905).

6 Sem falar na matraca que muitos sacolejavam enquanto caminhavam, chamando atenção para si e suas mercadorias.

7 Entre as mercadorias que a firma de Chediac repassava aos mascates constavam toaletes para senhoras, como "perfumaria da marca Fantasia, pó de arroz e sabão redondo".

8 Texto com grafia atualizada pelo autor. Este procedimento será adotado, daqui em diante, em todas as citações de época.

9 Em 20 minutos de caminhada desde a rua Nova, chegase à rua Lima e Silva, na Cidade Baixa, à qual deveria estar se referindo a reportagem. 
10 Segundo Moelecke (2013, [s. p.]), o diploma de Naaman fora expedido por uma universidade de Paris. No entanto, apesar de não termos conseguido acesso ao documento, é provável que seu diploma seja, na verdade, da Universidade Saint Joseph, de Beirute, famosa por ter enviado ao Brasil diversos médicos e intelectuais da colônia no início do movimento migratório. A esse respeito, ver: Lacaz, 1982.

$11 \mathrm{O} 4^{\circ}$ Distrito da capital foi um importante bairro industrial e operário de Porto Alegre. O local foi responsável pelo impulso inicial da forte industrialização do Sul do Brasil. Ver: Fortes, 2004.

12 Os dados de nosso microcosmo construído no Arquivo Nacional mostram uma preponderância significativa de presença masculina se comparada ao número de mulheres imigrantes. Dos 753 casos levantados, 522 eram homens, 357 deles casados, 141 solteiros, 23 viúvos e um desquitado. As profissões de comerciante e ambulante, somadas, lideravam com folga $(65 \%)$ o total das ocupações, especialmente entre os casados com registro de chegada anterior a 1920. As outras profissões citadas no cadastro foram as de criador; agricultor; industrial; horticultor; operário; funcionário e empregado rural. Em Porto Alegre, encontramos 187 comerciantes, dos quais 144 casados, 37 solteiros e seis viúvos. Entre os 51 homens que se declararam ambulantes, 26 eram casados, 22 solteiros e três viúvos. No cômputo geral do estado, contamos 352 comerciantes (entre homens e mulheres), 17 comerciários, 16 operários, 13 agricultores, 10 caixeiros viajantes, nove barbeiros, cinco alfaiates, cinco proprietários, quatro fotógrafos e quatro garçons. Completam as profissões declaradas, com pelo menos dois representantes, as seguintes ocupações: confeiteiro, carpinteiro, carroceiro, jornaleiro, feirante, ferroviário, sapateiro, fiscal e condutor de bondes, padeiro, porteiro, quitandeiro, vendedor, além de um imigrante que se declarou capitalista. A seleção ainda indicou a presença de 231 pessoas do sexo feminino, representando $31 \%$ do total, ou uma proporção de aproximadamente dois homens para cada mulher. Das 231 mulheres, 132 se declararam casadas, 61 solteiras, 34 viúvas e quatro desquitadas. Donas de casa eram a maioria. Entre as que declararam trabalhar, havia modistas, agricultoras, costureiras, ambulantes e comerciantes. Importante frisar que em nosso demonstrativo, 169 mulheres se declararam donas de casa.

13 "Cabeça de Porco" era um famoso e vasto cortiço no centro do Rio de Janeiro, por este motivo, os cortiços em todo país ganharam esse sinônimo.

14 As ruas do primeiro bairro citado com maior presença desses imigrantes eram a Voluntários da Pátria e a Cristóvão Colombo; e as do segundo, as ruas Lima e Silva e José do Patrocínio.

15 De acordo Franco (1992), muitas ruas de Porto Alegre já estavam bem servidas de infraestrutura de transporte urbano, saneamento básico, luz elétrica e sólidas construções, sobrados e prédios diversos, próprios para lojas, desde o fim do século XIX.

16 Aqui nos referimos ao bairro de São João cuja urbanização é iniciada na década de 1920. A avenida
Cascata e imediações, - atual Professor Oscar Pereira, acontece nas próximas décadas.

17 O bairro de São João dista cerca de oito quilômetros do centro, enquanto o da Glória cerca de quinze.

18 Nossa investigação contemplou apenas duas escolas da capital: os colégios Anchieta e Rosário. Essas escolas, além de serem os educandários particulares mais antigos de Porto Alegre, são os únicos que mantém seus registros iniciais e se encontram abertos até hoje. Apesar de reconhecermos a fragilidade dos dados obtidos, que não tabulou o de outras instituições públicas e particulares mais populares, acreditamos que, ainda assim, eles são representativos de uma elite econômica do estado até a década de 1940.

19 A fonte utilizada foi o Relatório do Ginásio Anchieta em Porto Alegre, Rio Grande do Sul. A publicação, editada ao fim de cada ano escolar desde 1890, trazia uma justificativa para o currículo adotado e um memorial para cada disciplina; uma pequena biografia de cada professor; regimento e regras internas da escola; preços e condições de matrícula; crônicas, fotografias diversas, divulgação de eventos variados como viagens, competições esportivas, exercícios militares, mas também relatórios e premiações dos alunos de cada ano letivo. Havia ainda uma lista nominal dos alunos matriculados em cada ano letivo.

20 A pesquisa foi feita por nome e sobrenome.

21 Neste ano aparece Moacyr Simon, do curso elementar, conquistando o prêmio de honra, e Jorge Maluf, do $5^{\circ}$ ginasial, com o prêmio de menção honrosa pelo conjunto de matérias.

$22 \mathrm{O}$ internato funcionava no prédio ao lado da sede da escola. O custo anual de um aluno matriculado no Colégio era de um conto e 500 mil-réis, valor bastante significativo para época.

23 Logo atrás figuravam José Elias Kalil, com 687 pontos; Nesralla Mansur Abraão, com 685; e Anis Jorge Aidar, com 629.

24 Uma parte desses sobrenomes era listada como proprietários de comércio árabe em Porto Alegre. Alguns nomes também figuram na lista de sócios-fundadores do Clube Sírio-Libanês (década de 1920), da Sociedade Libanesa de Porto Alegre (década de 1930) e da Sociedade Síria (década de 1940).

25 Aqui, nossa fonte foi a revista Ecos Rosariense, editada pelo Colégio e disponível em: <http://colegiomarista.org. $\mathrm{br} /$ rosario/exalunos/versoes-mais-antigas-do-ecos-saopublicadas-online>. Acesso em: 22 nov. 2016.

26 Conforme se pode verificar, nossa pesquisa lança um olhar exclusivo para a educação formal de rapazes de origem sírio ou libanesa, isso porque ambas escolas analisadas não eram mistas e os colégios para moças eram escassos e não mantinham relação de alunas na época investigada.

$27 \mathrm{Na}$ década de 1930 os primeiros descendentes de sírios formaram-se pela Faculdade de Medicina de Porto Alegre (futura UFRGS). Assim, por exemplo, Elias Buais 
e Elias José Kanan concluíram o curso em 1932; Chaphik Saadi, em 1934; Antônio Simão Saad Ralmae Allam; Elias Foedi Saadi; João Rechden; José Elias Kalil, em 1939. Na Faculdade de Direito, Brasil Seadi aparece em 1931, seguido por Abbadé dos Santos Ayub, formado em 1933, José Mansur Filho, formado em 1938 e Abelardo José Nácul, formado em 1939.

\section{Referências}

ALMEIDA, Ludmilla Savry. Sirios e libaneses: redes familiares e negócios. In: BORGES, Celia Maria (org.). Solidariedades e Conflitos. Histórias de Vida e Trajetórias de Grupos em Juiz de Fora. Juiz de Fora: Editora UFJF, 2000.

BACCAR, Muhamed. [Depoimento ao autor]. Rio de Janeiro, 2003.

BRUM, Rosemary F. Uma cidade que se conta. Imigrantes italianos e narrativas no espaço social da cidade de Porto Alegre nos anos 20-30. São Luiz: EDUFMA, 2009.

CABRAL, Claudia. Tipologias Comerciais em Porto Alegre: da rua comercial ao shopping center. Porto Alegre: PPG Arquitetura e Urbanismo Dissertação de Mestrado UFRGS, 1996.

COLÉGIO ANCHIETA DE PORTO ALEGRE. Relatório do Ginásio Anchieta em Porto Alegre, Rio Grande do Sul. Porto Alegre: Colégio Anchieta, 1890.

CORBINOS, Lorenzo Agar. El comportamento urbano de los imigrantes árabes em Chile. EURE, v. IX, n.27, 1983.

ECOS ROSARIENSE, editada pelo Colégio e disponível em: <http://colegiomarista.org.br/ rosario/exalunos/versoes-mais-antigas-do-ecossao-publicadas-online >. Acesso em: 22 nov. 2016.

FORTES, Alexandre. Nós do quarto distrito: a classe trabalhadora porto-alegrense e a era Vargas. Rio de Janeiro: Editora Garamond, 2004

FRANCO, Sérgio da Costa. Porto Alegre e seu comércio. Porto Alegre: Associação Comercial de Porto Alegre, 1992.

Guia Histórico de Porto Alegre. Porto Alegre: Editora da UFRGS) /Prefeitura Municipal, 1988.

GRANDE CONFlito. Correio do Povo, Porto Alegre, p. 1, 13 jan. 1898.
HAJJAR, Claude. Imigração árabe: 100 anos de reflexão. São Paulo: Ícone, 1985.

KNOWLTON, Clark. Sírios e libaneses em São Paulo: ascensão social e mobilidade espacial. São Paulo: Anhembi, 1960.

JOÃO, Rafique. [Depoimento ao autor]. Porto Alegre, 2015.

LESSER, Jeffrey. A negociação da identidade. São Paulo: Editora da USP, 2001.

From pedlers to proprietor: Lebanese, Syrian and Jewish immigration in Brazil In: HOURANI, Albert; SHEHADI, Nadim. The Lebanese in the world: a century of emigration. London and New York: I.B.Tauris and St.Martins Press, 1992.

LOGROÑO-NARBONA, Maria Del Mar. The development of nationalist identities in French Syria and Lebanon: a transnational dialogue with Arab immigrants to Argentina and Brazil, 19151929. Santa Barbara: University of California, 2007.

MOELECKE, Germano. As Ruas de São Leopoldo. VS Jornal, São Leopoldo, set. 2013.

NOAL FILHO, Valter Antônio; FRANCO, Sergio Costa. Os viajantes olham Porto Alegre. Porto Alegre: Anaterra, 2004. 2 vls.

NUNES, H. A imigração árabe em Goiás: 1880 - 1970. Dissertação de Mestrado (Instituto de História) Universidade de São Paulo: USP, 1986.

PESAVENTO, Sandra. RS: Os pobres da cidade Porto Alegre: Editora da UFRGS, 1994.

PINTO, Paulo Gabriel Hilu da Rocha. Árabes no Rio de Janeiro: uma identidade plural. Rio de Janeiro: Cidade Viva, 2010. (Série Imigrantes no Rio de Janeiro).

SCHILLING, Suzana Porcello. Sociedade Libanesa de Porto Alegre: Uma História a ser lembrada. Sociedade Libanesa de Porto Alegre: Editora Via Norte, Porto Alegre, 2007.

TRUZZI, Oswaldo M.S. Patrícios: Sírios e Libaneses em São Paulo: Hucitec, São Paulo, 1997.

Sírios e Libaneses e seus descendentes na Sociedade Paulista IN: FAUSTO, Boris (ORG) Fazer a América. EDUSP: São Paulo, 1999. 